\title{
Aerosol Climate Change Connection (AC3) Special Issue: An Overview
}

\author{
Abhijit Chatterjee ${ }^{*}$, Panuganti C.S. Devara ${ }^{2}$, Rajasekhar Balasubramanian ${ }^{3}$, Daniel A. Jaffe ${ }^{4}$ \\ ${ }^{1}$ Environmental Sciences Section, Bose Institute, Kolkata 700054, India \\ ${ }^{2}$ Amity Centre for Ocean-Atmospheric Science and Technology, Amity University Haryana, Manesar, Gurgaon 122413 , \\ India \\ ${ }^{3}$ Department of Civil and Environmental Engineering, National University of Singapore, Singapore 117576, Singapore \\ ${ }^{4}$ Department of Atmospheric Sciences, University of Washington Seattle, Seattle, WA 98195, USA
}

\begin{abstract}
Bose Institute, a premiere scientific research organization under Ministry of Science and Technology, Govt of India organized an international conference on "Aerosol Climate Change Connection (AC3)" held in Darjeeling, India during 25-27 April, 2017. AAQR is publishing a special issue on AC3 based on the major themes of the conference covering optical, radiative and chemical properties of composite and carbonaceous aerosols and the ground-based and remote sensing of aerosols. The papers accepted in this special issue are of good scientific merits and are useful for the scientific community working in the field of aerosol science and technology.
\end{abstract}

Keywords: AC3; Aerosol; Climate change; Himalaya.

\section{INTRODUCTION}

The importance of the study of atmospheric aerosols lies in their ability to alter the Earth-atmosphere radiation budget by scattering and absorbing solar radiation and influencing the process of the formation of cloud and precipitation. It is well known that absorbing/scattering of solar radiation by aerosols is the direct radiative effect of aerosols whereas aerosols indirectly can increase the cloud life-time and decrease precipitation (cloud lifetime effect), can increase the number of cloud droplets and decrease the radii (cloud albedo effect) and absorb radiation followed by re-emitting thermal radiation and evaporation of clouds (semi direct effect). The uncertainties related to aerosols indirect effects are larger than the aerosols direct effect because of poor knowledge of aerosol-cloud interaction, poor database on aerosol and cloud size distributions, uncertainties in model simulation etc.

The Indian subcontinent is known to be a regional aerosol hot spot for aerosols (Tiwari and Singh, 2013). The Indian landmass has plain land regions, coastal regions, arid and semi-arid regions as well as the mountainous plateaus. India experiences tropical and subtropical climatic conditions with extreme temperatures, rainfall, and humidity

\footnotetext{
* Corresponding author.

Tel.: (+91) 9051585800

E-mail address: abhijit.boseinst@gmail.com
}

regulating the physical and chemical characteristics of aerosols. Earlier studies have shown a large spatiotemporal variability in aerosol characteristics as well as in precipitations/monsoon rainfall in India. It was also reported that aerosols generating from biomass burning/crop residue burning over western part of Indo-Gangetic Plain (IGP) can be transported all the way to the eastern part of Himalaya and influence the cloud formation. Light absorbing aerosols are also found to be accumulating over the Tibetan plateau and this results in elevated heating and advancement of the Indian summer monsoon. Thus, the Indian subcontinent is an ideal region for the study of aerosol-cloud-precipitation and climate interactions.

\section{AEROSOL CLIMATE CHANGE CONNECTION (AC3): THE CONFERENCE AND THE SPECIAL ISSUE}

Bose Institute, a premiere scientific research organization under Ministry of Science and Technology, Govt of India has set-up an observatory for continuous monitoring of air pollutants, meteorological parameters, LIDAR-based studies and other remote sensing observations over a high altitude station, Darjeeling ( $2200 \mathrm{~m}$ asl) in the eastern Himalayan region of India since 2005. On the occasion of celebrating 100 years of Bose Institute, an international conference was organized named the "International Conference on Aerosol Climate Change Connection (AC3)" held in Darjeeling during 25-27 April, 2017. A total of 80 participants from India and abroad were present at the conference and 
71 papers were presented during the meeting. The major themes of the conference were 1) optical and radiative properties of aerosols, 2) remote sensing of aerosols, 3 ) formation, transport and deposition of carbonaceous aerosols, 4) role of aerosols on cloud and precipitation, 5) chemical characterization of aerosols and 6) aerosols over Himalayan and non-Himalayan high altitude and remote stations.

The editorial office of the journal Aerosol and Air Quality Research (AAQR) has published a special issue with the theme of the conference "Aerosol Climate Change Connection (AC3)" where significant numbers of papers were submitted out of which 13 papers were accepted after vigorous peer-review processes. All the submitted papers in this special issue were either presented in this conference or relevant to the theme of the conference.

\section{SUMMARY OF THE PAPERS IN AC3 SPECIAL ISSUE}

Aerosols of natural and anthropogenic sources play significant role in the perturbation of the earth's radiation budget having significant implications for climate change. The studies on the optical and radiative properties of aerosols through ground based and remote sensing observations are of utmost importance in the context of regional climate change.

Bansal et al. (2019) studied the aerosol characteristics over an urban atmosphere at western Indo-Gangetic Plain. They observed higher fine mode aerosol loading during post-monsoon and winter compared to summer. The variations in the AOD values as well as the Angstrom exponent were consistent with the fine mode aerosols variations. They also observed higher black carbon mass concentration during winter. The single scattering albedo derived from the OPAC (Optical Properties of Aerosols and Clouds) model varied from 0.890 to 0.947 with higher values in summer. They also derived the clear-sky direct atmospheric aerosol radiative forcing (ATM ARF) by the SBDART (Santa Barbara DISORT Atmospheric Radiative Transfer) model over the study region. The results give us information on the impact of composite as well as carbonaceous aerosols on the regional climate.

Other than the light-absorbing species black carbon, some organic species are generated in the atmosphere through secondary processing of primary anthropogenic emissions called. This aerosol is called brown carbon $(\mathrm{BrC})$ and also absorbs solar radiation and can alter the radiation budget. Zhang et al. (2019) conducted a study on the role of BrC on the light absorption using multi-wavelength Aethalometer. They quantitatively estimated the light absorption by $\mathrm{BrC}$ using an improved Absorption Angstorm Exponent (AAE) based method. They reported significant contribution ( $\sim 40 \%)$ of $\mathrm{BrC}$ from primary emissions to the light absorption by aerosols.

Krishna et al. (2019) performed a study where they integrated the MODIS AOD retrievals and simulations from the WRF-Chem model for ground based $\mathrm{PM}_{2.5}$ concentrations at $36 \mathrm{~km}$ resolutions across India. They also compared and correlated the satellite retrieved $\mathrm{PM}_{2.5}$ concentrations with 15 ground based observations in India. They reported strong correlation $(77 \%)$ for monthly data comparison and moderate to good correlation (0.45$0.75 \%$ ) for daily basis comparison. It is also important to understand the radiative forcing and its efficiency for the individual types of aerosols emitted from different sources.

Fawole et al. (2019) estimated the direct radiative forcing and the radiative forcing efficiency for different types of aerosols like desert dust, biomass burning, and, for the first time, the aerosols generated due to gas flaring near an AERONET site, Ilorin in Nigeria during West Africa Monsoon period. They observed that the direct radiative forcing of the desert dust aerosols was the highest but the radiative forcing efficiency was the lowest. However the radiative forcing of the biomass burning aerosols was much closed to that of desert dust aerosols.

Katsanos et al. (2019) conducted a one-year study (2016-2017) to examine the optical properties of different types of aerosols in an urban environment in Athens, Greece. They observed higher loading of fine mode absorbing aerosols in winter contributed by domestic heating, whereas they found greater loading from aged aerosols transported from regional source regions during summer. They also observed prominent diurnal variations of aerosols during winter, whereas no significant diurnal variation was observed in summer. A significant contribution of biomass burning aerosols from the forest fire was observed in winter. They reported a nearly $50 \%$ contribution of organic components in the total fine mode aerosols, followed by the contribution of sulphate and nitrate.

It is of paramount importance to understand the role of aerosols and their components in the formation of fog, reduced visibility and in-fog scavenging. Safai et al. (2019) performed a study on the aerosol-fog interaction at the international airport near New Delhi, India. They measured $\mathrm{BC}$ mass concentrations as well as aerosol absorption and scattering coefficients before, during and after the foggy period during winter 2015-2016. They reported higher BC, absorption and scattering coefficients before and during the initial phase of the foggy period. They also reported significant in-fog scavenging of aerosols when the fog sustained for a longer time period. They also observed good correlations between the aerosols and cloud condensation nuclei indicating an important role of the measured aerosols to form fog droplets. This dataset can significantly contribute to the scientific knowledge on the role of aerosols of different types and source types in the formation of the fog which would in turn help us to better predict the foggy episodes for air traffic management.

Sota et al. (2019) performed a laboratory study to measure the organic and elemental carbonaceous aerosols from cook stoves in West Africa. They used different types of stoves using different wood types. They observed that the emission factors for organic and elemental carbon for the wood species Dimb is higher than the other wood species Filao. Dimb and Filao (also called Australian Pine tree) are the important firewood species used in West African villagers. They reported that the warming associated with 
the Rocket stoves is much higher than the three-stone fire. Their study definitely adds to an improved understanding of emissions and emission inventories at regional and national levels.

The source apportionment of aerosols based on the rare earth elements is highly limited. Hu et al. (2019) analyzed the rare earth elements in $\mathrm{PM}_{2.5}$ aerosols over a coastal city Quanzhou in China. They used the ratio of $\mathrm{Nd}$ isotopes and the light to heavy rare earth elements to determine sources, including fossil fuel emissions, coal combustion and a smaller contribution from the soil dust.

It is also important to investigate the changes in the chemical and optical properties of aerosols during heavy pollution episodes. $\mathrm{Yu}$ et al. (2019) characterized the chemical and optical properties of aerosols over an urbanindustrial region of Nanjing city in China during heavy pollution periods. They reported that the aerosol levels were within the national ambient air quality standard of China for only $30 \%$ of the days and that the major water soluble ionic species were ammonium, nitrate and sulphate. Ammonium nitrate and organic matter were found to make the greatest contribution to light absorption. High values of the organic to elemental carbon ratio were reported for the heavy pollution episodes.

Begum and Hopke (2019) characterized the fine mode aerosols chemically and found out the major sources using positive matrix factorization model for a long-term period (1997-2015) in Dhaka, Bangladesh. Priyadharshini et al. (2019) performed a thorough chemical characterization of sub-micron aerosols over Kolkata, a tropical urban atmosphere in India. They observed a strong influence of biomass burning aerosols during premonsoon and postmonsoon period, when non-sea-potassium increases by several times. The major sources of organic carbon was found to be biomass and coal burning, whereas the sources of elemental carbon were found to be industrial and vehicular emissions.

The biomass burning plume transported from regional source regions effectively changes the physical and chemical properties of aerosols. Shahid et al. (2019) performed a study on the impact of biomass burning plume on the aerosol chemistry over a residential site in Islamabad, Pakistan. They analyzed aerosols for various biological aerosols like levoglucosan, primary and secondary saccharides, anhydrosaccharides etc. They reported that the contribution of the anhydrosaccharides is much higher than the primary saccharides. The impact of the biomass burning plumes on the size segregated aerosol chemistry was also studied by Ghosh et al. (2019) over Kolkata, a topical urban atmosphere at indo-Gangetic Plain. They observed significant increase in the ultrafine and superfine aerosols concentration due to the advection of biomass burning plumes from the Eastern Ghat regions in southeast coast of India. They reported significant changes in the mass-size distributions of the ionic species due to these biomass burning plumes. They also reported that the seasalt aerosols (transported from the Bay of Bengal) interacted with the biomass burning plume (transported from the Eastern Ghat region) leading to the significant depletion of chloride from the sea-salt particles.

Hapidin et al. (2019) studied the characterization of an aerosol chamber for the evaluation of the sensors for particulate matter monitoring. They obtained an empirical equation to describe the aerosol concentration decay inside the chamber and the equation was used to predict the measurement time and the number of data points before conducting the experiment. They have also evaluated the performance of other standard aerosol monitors and found excellent correlations.

\section{CONCLUDING REMARK}

The AC3 conference was a successful event in true sense. Several research scientists pioneering in this field from India and abroad shared their knowledge in the field of aerosols and climate change. The papers accepted in this special issue are of good scientific merits and spanned over a wide range of studies. Guest editors would like to thank all the authors for submitting their papers and thank all the reviewers for reviewing the papers.

\section{REFERENCES}

Bansal, O., Singh, A. and Singh, D. (2019). Aerosol characteristics over the northwestern Indo-Gangetic Plain: Clear-sky radiative forcing of composite and black carbon aerosol. Aerosol Air Qual. Res. 19: 5-14.

Begum, B.A. and Hopke, P.K. (2019). Identification of sources from chemical characterization of fine particulate matter and assessment of ambient air quality in Dhaka, Bangladesh. Aerosol Air Qual. Res. 19: 118-128.

de la Sota, C., Viana, M., Kane, M., Youm, I., Masera, O. and Lumbreras, J. (2019). Quantification of carbonaceous aerosol emissions from cookstoves in Senegal. Aerosol Air Qual. Res. 19: 80-91.

Fawole, O.G., Cai, X., Pinker, R.T. and MacKenzie, A.R. (2019). Analysis of radiative properties and direct radiative forcing estimates of dominant aerosol clusters over an urban-desert region in West Africa. Aerosol Air Qual. Res. 19: 38-48.

Ghosh, A., Roy, A., Chatterjee, A., Das, S.K., Ghosh, S.K. and Raha, S. (2019). Impact of biomass burning plumes on the size-segregated aerosol chemistry over an urban atmosphere at Indo-Gangetic Plain. Aerosol Air Qual. Res. 19: 163-180.

Hapidin, D.A., Saputra, C., Maulana, D.S., Munir, M.M. and Khairurrijal, K. (2019). Aerosol chamber characterization for commercial particulate matter (PM) sensor evaluation. Aerosol Air Qual. Res. 19: 181-194.

Hu, G., Wang, S., Yu, R., Zhang, Z. and Wang, X. (2019) Source apportionment of rare earth elements in $\mathrm{PM}_{2.5}$ in a southeast coastal city of China. Aerosol Air Qual. Res. 19: 92-102.

Katsanos, D., Bougiatioti, A., Liakakou, E., Kaskaoutis, D.G., Stavroulas, I., Paraskevopoulou, D., Lianou, M., Psiloglou, B.E., Gerasopoulos, E., Pilinis, C. and Mihalopoulos, N. (2019). Optical properties of nearsurface urban aerosols and their chemical tracing in a 
Mediterranean City (Athens). Aerosol Air Qual. Res. 19: 49-70.

Krishna, R.K., Ghude, S.D., Kumar, R., Beig, G., Kulkarni, R., Nivdange, S. and Chate, D. (2019). Surface $\mathrm{PM}_{2.5}$ estimate using satellite-derived aerosol optical depth over India. Aerosol Air Qual. Res. 19: 2537.

Priyadharshini, B., Verma, S., Chatterjee, A., Sharma, S.K. and Mandal, T.K. (2019). Chemical Characterization of Fine Atmospheric particles of water-soluble ions and carbonaceous species in a tropical urban atmosphere over the Eastern Indo-Gangetic Plain. Aerosol Air Qual. Res. 19: 129-147.

Safai, P.D., Ghude, S., Pithani, P., Varpe, S., Kulkarni, R., Todekar, K., Tiwari, S., Chate, D.M., Prabhakaran, T., Jenamani, R.K. and Rajeevan, M.N. (2019). Two-way Relationship between aerosols and fog: A case study at IGI airport, New Delhi. Aerosol Air Qual. Res. 19: 7179.

Shahid, I., Kistler, M., Shahid, M.Z. and Puxbaum, H. (2019). Aerosol chemical characterization and contribution of biomass burning to particulate matter at a residential site in Islamabad, Pakistan. Aerosol Air Qual. Res. 19: 148-162.

Tiwari, S. and Singh, A.K. (2013). Variability of aerosol parameters derived from ground and satellite measurements over Varanasi located in the IndoGangetic Basin. Aerosol Air Qual. Res. 13: 627-638.

Yu, X., Shen, L., Xiao, S., Ma, J., Lü, R., Zhu, B., Hu, J., Chen, K. and Zhu, J. (2019). Chemical and optical properties of atmospheric aerosols during the polluted periods in a megacity in the Yangtze River Delta, China. Aerosol Air Qual. Res. 19: 103-117.

Zhang, G., Peng, L., Lian, X., Lin, Q., Bi, X., Chen, D., Li, M., Li, L., Wang, X. and Sheng, G. (2019). An improved Absorption Ångström Exponent (AAE)-Based method for evaluating the contribution of light absorption from brown carbon with a high-time resolution. Aerosol Air Qual. Res. 19: 15-24.

Received for review, November 30, 2018

Revised, December 15, 2018

Accepted, December 17, 2018 